\section{La Epidemia VIH en Tiempos de Pandemia: situación en Chile}

\section{The HIV Epidemic on Pandemic Times: Situation in Chile}

\section{Señor Editor,}

Es claro para todos que la pandemia de COVID-19 ha generado estragos a nivel mundial, no solo en lo sanitario, sino también lo económico, social y psicológico. A la fecha, en Chile se han registrado más de un millón y medio de personas infectadas, y cerca de 35 mil fallecidos. En este contexto, el sistema de salud se ve superado, teniendo que restringir las atenciones por otras patologías. De acuerdo con un informe del Colegio Médico de Chile, para 2020 hubo una disminución de $38 \%$ en las cirugías electivas, $38 \%$ en las consultas médicas especializadas y 7,24 veces más retrasos en el cumplimiento de garantías GES, en comparación con el año $2019^{1}$.

El panorama para las personas que viven con VIH es especialmente preocupante. Si bien la evidencia sobre comorbilidad entre la infección por VIH y por SARS$\mathrm{CoV}-2$ es contradictoria y no concluyente, las personas que viven con VIH tienen mayores factores de riesgo que pudieran facilitar el contagio de COVID-19 y desenlaces mortales de la enfermedad, tanto a raíz de ésta, como de otras complicaciones médicas, especialmente en quienes no reciben tratamiento o tienen un bajo recuento de células CD4, por lo que los cuidados en este grupo de la población deben extremarse. Debido a lo anterior, cabe preguntarse ¿qué ocurre en Chile con la epidemia de VIH, en tiempos de pandemia? Planteamos aquí tres áreas básicas que deben ser cubiertas con urgencia.

La prevención del contagio por VIH es un aspecto fundamental. Las pocas y criticadas iniciativas de educación sexual y comunicación social disponibles en Chile, en la actualidad son prácticamente inexistentes ${ }^{2}$ y el presupuesto nacional orientado a la prevención es mínimo ${ }^{3}$. Un ejemplo de ello es la campaña ministerial "Es positivo saber" y "Es positivo cuidarse", destinada a promover el uso de condón y la realización de la prueba para la detección del VIH, que alcanzó a estar vigente solo cuatro meses desde su lanzamiento. Esta prolongada ausencia entrega un preocupante mensaje a la población: el VIH dejó de ser un problema relevante de prevenir. De acuerdo con un informe de la Corporación Miles ${ }^{3}$ se ha observado una disminución de 29\% -respecto del 2019- en los exámenes procesados por el ISP, lo que evidenciaría un retroceso en las acciones de prevención secundaria. Recientemente se han realizado algunos esfuerzos relevantes en esta área, anunciándose el pasado 15 de julio desde la Subsecretaria de Salud
Pública, un nuevo programa para fomentar el testeo conjunto de VIH y COVID-19, con nuevos puntos de cribaje, pero que solo estarán disponibles en tres de las 16 regiones del país.

Un segundo tema es el tratamiento de las personas que viven con VIH. Según datos del Departamento de Epidemiología del Ministerio de Salud, para el año 2019 se notificaron 5.160 nuevos casos de VIH/ SIDA, significando un aumento de 30,9\% respecto al año $2018^{4}$. Adicionalmente, estas cifras reflejan un distanciamiento de las metas 90-90-90 de ONUSIDA ${ }^{2}$, ya que el 83,6\% de las notificaciones son en hombres ${ }^{4}$, con una limitación notoria de las mujeres en el acceso a servicios de detección temprana. En el contexto actual, esto se ve agravado por las barreras en la adherencia al tratamiento, asociadas al miedo al contagio por COVID-19 en los centros de atención en salud ${ }^{1,5}$, por lo que las políticas públicas debieran apuntar hacia la facilitación de atenciones ambulatorias para personas inmunodeprimidas.

Un tercer y último punto es la investigación. Si bien, es necesario y comprensible el aumento de la investigación centrada en COVID-19, preocupa el descenso de investigación enfocada en otras patologías. Un vistazo rápido a las publicaciones más recientes a nivel mundial en la base de datos Web of Science muestra que, en el período 2020-2021, el descriptor VIH acumula solo 25.768 resultados, inferior a otras patologías crónicas como obesidad (46.053) o diabetes (68.120), y muy inferior a "COVID" (134.378). En Chile, el escenario es mucho más precario, ya que se observan solo 26 resultados para el descriptor VIH, de los cuales 2 abordan determinantes psicosociales del contagio. La escasa investigación multidisciplinaria sobre el VIH en el territorio nacional ha sido señalada como una arista relevante en la situación epidemiológica² ${ }^{2}$.

Entendiendo que los desafíos que surgen en estos tiempos son múltiples y configuran un panorama complejo de abordar, es necesario agregar a la lista los tres focos mencionados. En primer lugar, es necesario aumentar las estrategias de prevención de la enfermedad y promoción de la salud, ya que la presencia de comorbilidades puede incrementar el riesgo de mortalidad y aumentar la saturación de los servicios de salud. Además, dado que el distanciamiento social, cuarentenas y restricciones comunitarias limitan el acceso a servicios de diagnóstico de $\mathrm{VIH}^{6}$, en este momento es clave asegurar el acceso a la prevención secundaria.

En segundo lugar, considerando el riesgo que supone la inmunosupresión para el contagio y mortalidad por COVID-19, resulta crucial garantizar la atención médica para personas que viven con VIH. Para ello es importante tener en cuenta las barreras estructurales, sociales y psicológicas para la atención, como el miedo de los pacientes al contagio de COVID-19 por asistir a servicios de salud ${ }^{5}$ o las limitaciones de los propios cen- 
tros de atención, debido a la saturación por atenciones asociadas a la pandemia ${ }^{6}$.

Finalmente, se debe promover el desarrollo científico en múltiples áreas y fomentar el trabajo interdisciplinar. Un adecuado abordaje de cualquier patología incluye la comprensión de las dinámicas subyacentes a las conductas para la prevención de la enfermedad, promoción de la salud y adherencia al tratamiento; solo así se pueden establecer intervenciones pertinentes.

Si bien fenómenos emergentes y urgentes, como la pandemia COVID-19, requieren de una atención especial y esfuerzos concentrados, no podemos olvidar que la epidemia de VIH en Chile no está superada. Las iniciativas en políticas públicas orientadas a la prevención conjunta, además de la reactivación y fortalecimiento de las redes asistenciales, son puntos claves para hacer frente no solo al COVID-19, sino también al VIH.

\section{Mauro P. Olivera del Río ${ }^{1,2, a, b}$, Natalia Salinas-Oñate ${ }^{1,2, c}$ \\ ${ }^{1}$ Departamento de Psicología, Universidad de La Frontera, Temuco, Chile.} ${ }^{2}$ Laboratorio de Cultura y Comportamiento. Doctorado en Psicología, Facultad de Educación, Ciencias Sociales y Humanidades, Universidad de La Frontera,

Temuco, Chile.

${ }^{a}$ Psicólogo, Licenciado en Psicología.

${ }^{b}$ Estudiante, Doctorado en Psicología.

'Psicóloga, Doctora en Psicología.

\section{Referencias}

1. Colegio Médico de Chile. El Impacto de COVID-19 en el Sistema de Salud y Propuestas para la Reactivación [In- ternet]. Chile: Colegio Médico de Chile; 2020 Agosto 19 [citado el 28 de junio de 2021]. 48 p. Disponible en: https:// www.colegiomedico.cl/wp-content/uploads/2020/08/reactivacion-sanitaria.pdf.

2. Wolff M, Pinto ME, Santolaya ME, Aguilera X, Child R. Evaluación de la infección por VIH en Chile: pronunciamiento del Comité VIH de la Académia Chilena de Medicina. Rev Med Chile 2020; 148 (6): 818-21. doi: 10.4067/ S0034-98872020000600818.

3. Corporación Miles. Tercer Informe sobre Derechos, Salud Sexual Reproductiva y Violencia de Género en Chile [Internet]. Chile: Corporación Miles; 2021 Abril [citado el 26 de julio de 2021]. 116 p. Disponible en: https://mileschile.cl/ cms/wp-content/uploads/2021/04/Tercer-informe-Corporaci $\% \mathrm{C} 3 \% \mathrm{~B} 3 n-M i l e s . p d f$.

4. Departamento de Epidemiología. Boletín Epidemiológico Trimestral: Virus de la Inmunodeficiencia Humana (VIH) SE 1-52 Año 2019 [Internet]. Chile: Ministerio de Salud, Gobierno de Chile; 2019 Diciembre [citado el 23 de julio de 2021]. Disponible en: http://epi.minsal.cl/wp-content/ uploads/2020/02/BET_VIH_2019.pdf.

5. Lazzerini M, Barbi E, Apicella A, Marchetti F, Cardinale F, Trobia G. Delayed access or provision of care in Italy resulting from fear of COVID-19. Lancet Child Adolesc Health. 2020; 4 (5): e10-e11. doi: 10.1016/s2352-4642(20)30108-5.

6. Jiang H, Zhou Y, Tang W. Maintaining HIV care during the COVID-19 pandemic. Lancet HIV. 2020; 7 (5): e308-9. doi: 10.1016/s2352-3018(20)30105-3.

\section{Correspondencia a:}

Natalia Salinas-Oñate

Av. Francisco Salazar 01145, Universidad de La Frontera. Temuco, Chile.

natalia.salinas@ufrontera.cl. 